\title{
Deus "sai do armário"? \\ algumas considerações teológicas sobre a homoafetividade
}

\author{
God "comes out of the closet"? \\ some theological considerations about homoaffectivity
}

Carlos Rafael Pinto*

\begin{abstract}
Resumo
Dentro e fora da Igreja Católica, nas últimas décadas, constata-se que a realidade homoafetiva clama atenção, sobretudo por estar intimamente associada à violência, exclusão, discriminação. À luz da experiência do Filho de Deus, vou me deixar guiar pela intuição, segundo a qual, na experiência homoafetiva, Deus "sai do armário". Por conseguinte, cabe-nos na reflexão teológica e no serviço apostólico reconhecer que Deus se revela também nessa realidade tendo, pois, que assumi-la como locus theologicus.
\end{abstract}

Palavras-chave

Revelação. Homoafetividade.

\begin{abstract}
Within and outside the Catholic church, in the last decades, one observes that the homoaffective reality cries out for attention, especially because it is intimately associated to violence, exclusion, discrimination. In light of the experience of the Son of God, I will let myself be guided by the intuition, according to which, in the homoaffective experience, God "comes out of the closet". Consequently, it is up to us in theological reflection and in apostolic service, to recognize that God reveals God's self also in this reality, thus, the need to assume it as a locus theologicus.
\end{abstract}

\section{Keywords}

Revelation. Homoaffectivity.

\section{Introdução}

Motivado pela temática da misericórdia proclamada pelo Papa Francisco: "o nome de Deus é misericórdia", ${ }^{1}$ pretendo tecer algumas considerações pastorais e teológicas a respeito

[Texto recebido em junho de 2018 e aceito em julho de 2018, com base na avaliação cega por pares realizada por pareceristas ad hoc]

* Mestre em Teologia (FAJE-BH). Graduado em Filosofia e Teologia (CES-JF). E-mail: crafapinto@gmail.com

1 PAPA FRANCISCO. O nome de Deus é misericórdia: uma conversa com Andrea Tornielli. São Paulo: Planeta, 2016. 
das experiências homoafetivas. ${ }^{2}$ Para isso, partirei da escuta atenta de alguns jovens homoafetivos (16-27 anos, de várias classes sociais) e da leitura de alguns escritos que ensaiam tanto uma nova abordagem católica da homoafetividade quanto uma Teologia gay.

Meu percurso terá como pressuposto a novidade da Teologia cristã, segundo a qual “Ele [Cristo Jesus], estando na forma de Deus não usou de seu direito de ser tratado como um deus, mas se despojou, tomando a forma de escravo. Tornando-se semelhante aos homens e reconhecido em seu aspecto como um homem" (Fl 2. 6-7). À luz da experiência do próprio Filho de Deus, vou me deixar guiar pela intuição que, desde o contato com os jovens, motivou-me a divagar sobre este tema: na experiência homoafetiva, Deus "sai do armário".

\section{Deus "sai do armário": sinal e interpelação de Deus na atualidade}

Realizado pela Igreja Católica, o Concílio Vaticano II (1962-1965) deixou bem claro que o dever da Igreja consiste em investigar, a todo o momento, os sinais dos tempos e interpretá-los à luz do Evangelho. ${ }^{3}$ Isso é algo que a Teologia Latino-Americana tem levado a sério, a ponto de, no dizer de Jon Sobrino, o presente tornar-se lugar da manifestação de Deus: "o histórico exerce a função de mediação da realidade de Deus; no histórico o próprio Deus se faz presente em sua realidade e em seus planos". ${ }^{4}$

Há décadas que as Conferências Gerais do Episcopado Latino-Americano têm apontado vários desses sinais na área social e procurado interpretá-los à luz da mensagem evangélica. No entanto, nas últimas décadas, tem emergido, dentro e fora da Igreja, uma realidade que clama atenção, sobretudo por estar intimamente associada à violência, exclusão, discriminação: a realidade homoafetiva. Por isso, compete à Teologia reconhecer que Deus se manifesta também nessa realidade tendo, portanto, que assumi-la como lugar teológico.

\section{Estado da questão}

Depois da escuta atenta de alguns jovens homoafetivos e da leitura dos textos de Alison e Musskopf, pude observar alguns elementos comuns no itinerário de descoberta

2 Consideramos o conceito de "experiência" em sua dimensão existencial, segundo a qual ela se refere sempre a um ato ou estado "provado" ou "vivido", imediata e diretamente captado pela consciência, daí o seu caráter vivo e insubstituível, opondo-se à especulação e ao pensamento puro. "A vida do sujeito manifesta-se na experiência, como o termo alemão muito bem exprime: Er-leben (experimentar): estar vivo quando algo acontece, estar vivo em confronto com o que está acontecendo em nós". LIBANIO, João Batista. Teologia da revelação a partir da modernidade. São Paulo: Loyola, 2012. p. 202.

3 VIER, Frederico (Coord.). Compêndio do Vaticano II: Constituições, Decretos, Declarações. 29.ed. Petrópolis: Vozes, 2000. "Constituição Pastoral Gaudium et Spes. Sobre a Igreja no mundo atual”, n. 4. Para esse ensaio, interessa-me ainda mais outra acepção dos sinais dos tempos: “O Povo de Deus, movido pela fé com que acredita ser conduzido pelo Espírito do Senhor, o qual enche o universo, esforça-se por discernir nos acontecimentos, nas exigências e aspirações, em que participa juntamente com os homens de hoje, quais são os verdadeiros sinais da presença ou da vontade de Deus" (GS 11).

4 SOBRINO, Jon. Como fazer Teologia. Proposta metodológica a partir da realidade salvadorenha e latinoamericana. Perspectiva Teológica, v. 21, p. 285-303, 1989. p. 286. 
da sexualidade homoafetiva. Um dos mais explícitos: aos poucos, praticamente todas as pessoas homoafetivas foram colocadas ou empurradas para "dentro do armário", em virtude das tipologias distorcidas de gays, das experiências sexuais nocivas, dos sentimentos de baixa autoestima e da ignorância e do preconceito. ${ }^{5}$

Isso fez emergir algumas questões que acabaram inspirando e alimentado minha intuição: até que ponto a expressão metafórica "sair do armário" contempla eficazmente o itinerário da experiência homoafetiva? Em caso afirmativo, a quem ela se refere: ao jovem homoafetivo ou à cultura? A partir da experiência da contemplação da encarnação do Filho de Deus, 6 faz sentido pensar num Deus que “saia do armário"?

\section{Complexidade das experiências}

Em alguns casos, num momento anterior à descoberta da homoafetividade, alguns jovens viveram um período de perturbação interior por causa das experiências nefastas que tiveram, tanto com homens quanto com mulheres. Os que foram molestados ou violentados por figuras de autoridade chegaram a expressar isso de forma dura: "imagine um ladrão que invade sua casa; foi assim que me senti, invadido e violentado".

Por outro lado, vários jovens relataram descobrir os significantes e os valores da experiência homoafetiva a partir do cultivo da intimidade pessoal e da relação amorosa. Nesses casos, tal experiência foi expressão de cuidado, ternura, delicadeza, afeto, carinho, respeito, diálogo, cumplicidade, compromisso.

\section{Tópicos da poesia dos corpos}

Foi relevante notar que, segundo as narrativas de alguns jovens quanto às suas experiências afetivas, eles mesmos observaram que têm consciência de terem diante de si não apenas um "corpo nu" de alguém do mesmo sexo, mas uma carnalidade "prenha" de história, dramas, sonhos, pensamentos e afetos; em síntese, um corpo poético. ${ }^{7}$

Sem obscurecer a própria singularidade, nessa relação erótica acontece espontaneamente uma dinâmica de desejos, agraciando-se mutuamente, como ilustra a maravilhosa poesia Gostoso demais, de Dominguinhos e Nando Cordel.

Tô com saudade de tu, meu desejo

Tô com saudade do beijo e do mel

5 ALISON, James. Fé além do ressentimento: fragmentos católicos em voz gay. São Paulo: É Realizações, 2010; MUSSKOPF, André Sidnei. Uma brecha no armário: propostas para uma teologia gay. São Leopoldo: CEBI/Fonte Editorial, 2015.

6 Segundo o livro dos Exercícios Espirituais de Santo Inácio de Loyola, as Três Pessoas divinas decretaram em sua eternidade que a segunda Pessoa da SS. Trindade se fizesse homem. SANTO INÁCIO, de Loyola. Exercícios Espirituais. São Paulo: Loyola, 2015. p. 102.

7 Considera-se "poética" uma condição de possibilidade de perceber e, ao mesmo tempo, extrair riquezas da realidade. RILKE, Rainer M. Poemas e cartas a um jovem poeta. Rio de Janeiro: Nova Fronteira, 2013. p. 80. 
Do teu olhar carinhoso

Do teu abraço gostoso

De passear no teu céu.

É tão difícil ficar sem você

O teu amor é gostoso demais

Teu cheiro me dá prazer

Quando estou com você

Estou nos braços da paz.

Pensamento viaja

E vai buscar meu bem-querer

Não posso ser feliz, assim

Tem dó de mim

O que é que eu posso fazer. ${ }^{8}$

Deveras, na relação afetiva, seja homo, seja hétero, revela-se a beleza erótica da carnalidade, que não se determina por cálculos aritméticos, isto é, dois corpos que se penetram não se fundem, tampouco formam um corpo, mas esses dois corpos permanecem dois e, ao mesmo tempo, "um" no tocante à experiência do amor. ${ }^{9}$

\section{Alguns elementos teológicos das experiências homoafetivas}

No processo de descoberta de sua orientação afetivo-sexual, os jovens de orientação homoafetiva desejam reconhecer-se e acolher-se como gays e, ao mesmo tempo, como filhos desejados e amados por Deus. ${ }^{10}$ Se considerarmos que a única certeza que nos irmana a todos é a de que somos todos filhos de Deus, o que tais jovens desejam é mais do que justo.

Para muitos jovens homoafetivos, o amor de Deus se revela11 também na relação de hospitalidade dos corpos que se aproximam, se encontram, se tocam, se beijam, se acariciam e se penetram. Nessa relação, cada qual se tornaria um santuário, isto é, um

Gostoso

Demais.

Disponível

em: <https://www.letras.mus.br/dominguinhos/45557>. Acesso em: 10 abr. 2018.

9 Conforme Paul Ricouer, o desejo como Eros não pertence à ordem teorética, mas é da ordem da afectividade (páthos) que é, por experiência, pré-científico, pré-linguístico ou pré-jurídico, que se comunica como linguagem simbólica da sexualidade: "quando dois seres se enlaçam, não sabem o que fazem; não sabem o que buscam, não sabem o que encontram". RICOEUR, Paul. A Maravilha, o Descaminho, o Enigma. Revista Paz e Terra, v. 5, 1967. p. 36.

10 Claude Besson oferece uma significativa contribuição tanto para a reflexão teológica como para a criação de uma pastoral voltada para as pessoas homossexuais. Destaca-se, nessa obra, o $6 .^{\circ}$ capítulo, sobre a necessidade de uma interpretação lúcida e crítica de algumas passagens bíblicas. BESSON, Claude. Homossexuais católicos: como sair do impasse. São Paulo: Loyola, 2015.

11 Segundo Libanio, "a revelação é mediatizada pela história no seu processo e nas suas diferentes manifestações. A história, seja enquanto a trama de ações e relações humanas, seja enquanto princípio de compreensão, é criação dos homens e por isso cai sob o juízo da ação do Deus revelador". LIBANIO, 2012, p. 289. 
espaço sagrado, onde o penúltimo ${ }^{12}$ véu do escondimento pode cair por terra e, consequentemente, fazer que a beleza infinita do mistério de Deus se descortine simbolicamente.

No itinerário pessoal que muitos jovens homoafetivos percorrem, nota-se que experimentam sinais da ação salvífica de Deus, pois a beleza infinita de Deus, "tão antiga e tão nova",13 irrompe-se também na intimidade homoafetiva, a partir da relação de amor, carinho, ternura, reciprocidade, liberdade, cuidado. Percebe-se que, nessa comunhão, um se doa ao outro, ou melhor, um hospeda o outro, descobrindo um dom em si e para si mesmo e, por desdobramento, fazendo-se dom de si para o outro.

A experiência da relação amorosa entre gays pode gestar-se na graça de Deus, no sentido de que Deus age provocando, inclusive, um movimento para a hospitalidade dos corpos frágeis e vulneráveis, conforme ilustra a formidável poesia Dona do dom, de Chico César:

Dona do dom que Deus me deu Sei que é ele a mim que me possui

$\mathrm{E}$ as pedras do que sou dilui

E eleva em nuvens de poeira

Mesmo que às vezes eu não queira

Me faz sempre ser o que sou e fui.

\section{$[\ldots]$}

Presa do dom que Deus me pôs

Sei que é ele a mim que me liberta

E sopra a vida quando as horas mortas

Homens e mulheres vêm sofrer de alegria

Gim, fumaça, dor, microfonia

E ainda me faz ser o que sem ele não seria.

\section{$[\ldots]$}

Plena do dom que Deus me deu

Sei que é ele a mim que me ausenta

E quando nada do que eu sou canta

E o silêncio cava grotas tão profundas

Pois mesmo aí na pedra ainda

Ele me faz ser o que em mim nunca se finda.

Eu quero, quero, quero, quero ser sim

Essa ave frágil que avoa no sertão

12 Refiro-me ao "penúltimo" e não ao "último" véu, porque, a meu ver, a relação homoafetiva conserva um vestígio da ordem do mistério.

13 SANTO AGOSTINHO. Confissões. São Paulo: Paulus, 2004. p. 295. 
O oco do bambu

Apito do acaso, a flauta da imensidão. ${ }^{14}$

De acordo com a perspectiva da Teologia cristã, pode-se considerar que essa experiência de "doação" vem de Deus. ${ }^{15}$ Isso significa que Deus desperta, antes de qualquer coisa, um movimento interior para acolhida da própria homoafetividade também como dom. ${ }^{16}$ Além do mais, Deus mesmo pode inspirar uma relação oblativa entre gays, como símbolo do amor de Deus pelo ser humano.

Considera-se, nesse sentido, que ser gay ou sentir-se gay não é um conceito, tampouco uma definição. É muito mais do que uma orientação ou um comportamento, mesmo que, por um longo período, alguns neguem ou resistam acolher sua orientação sexual por inúmeros motivos. Trata-se de um modo de ser, de uma "condição antropológica". ${ }^{17}$ De qualquer modo, muitos jovens já experimentam, na orientação homoafetiva, sinais da presença salvífica e misericordiosa de Deus. ${ }^{18}$

Por conseguinte, tomando como pressuposto teológico tanto a meditação da Kenose, em Fl 2.6-7, quanto a contemplação da encarnação do Filho de Deus, ${ }^{19}$ intuímos teologicamente que, no mundo homoafetivo, Deus "sai do armário". Ou seja, a partir da autorrevelação de Deus na "carne humana", Deus se autoimplica também na "carnalidade" homoafetiva,"20 motivo pelo qual, quando um gay "sai do armário", pode implicar teologicamente que Deus mesmo "sai do armário", revelando sinais da experiência profunda de sua misericórdia: encontro e compaixão, proximidade e beleza, amor e cuidado, ternura e salvação.

14 CÉSAR, Chico. Dona do Dom. Disponível em: <https://www.vagalume.com.br/maria-bethania/dona-dodom.html>. Acesso em: 10 abr. 2018.

15 Identifica-se "dom de si" com uma saída de si em direção ao outro. LIBANIO, João Batista. A escola da liberdade: subsídios para meditar. São Paulo: Loyola, 2010. p. 129

16 Para James L. Empereur, "a homossexualidade é um dos dons mais significativos de Deus para a humanidade. Ser gay ou lésbica é ter recebido uma bênção especial de Deus". EMPEREUR, James. L. Direção espiritual e homossexualidade. São Paulo: Loyola, 2006. p. 1.

17 VIDAL, Marciano. Ética da sexualidade. São Paulo: Loyola, 2002. p. 119.

18 A partir do hino cristológico pré-paulino em $\mathrm{Cl}$ 1.15-20, Libânio observa que "se todas as coisas foram criadas em, por e para Cristo, significa que elas têm um dinamismo revelador de Cristo. Estão marcadas por sua origem e finalidade crística. Por vir dele, trazem suas pegadas. Por caminhar para ele, vão revelando e traçando o projeto salvífico de Deus". LIBANIO, 2012, p. 257.

19 Para Karl Rahner, uma vez que o Logos divino é a Palavra abreviada de Deus, por consequência, o homem se torna a cifra do próprio Deus (RAHNER, Karl. Curso fundamental da fé: introdução ao conceito de cristianismo. São Paulo: Paulus, 1989. p. 268). Todavia, quanto ao ato de fé, Libanio nos ensina que "Deus não pode ocupar o lugar do ser humano. Não é Deus quem crê pelo e no lugar do homem, mas sim é o homem (...). A confissão de fé é um ato do ser humano e por isso deve respeitar-lhe a estrutura humana" (LIBANIO, João Batista. Eu creio, nós cremos: tratado da fé. São Paulo: Loyola, 2000. p. 151).

20 Empereur considera que, quando uma pessoa é homossexual, "Deus está presente de maneira homossexual". EMPEREUR, 2006, p. 2-3. 


\section{Considerações finais}

Posto que "a Palavra se fez carne e veio morar entre nós" (Jo 1.14) e que o seu Espírito habita em nós (1 Cor 6.19), podemos considerar a carnalidade humana como "coabsoluta" de Deus. Podemos, pois, aí reconhecer que a descoberta da homoafetividade também permite, antes de qualquer coisa, experimentar o mistério de Deus na própria carne. Assim sendo, a experiência homoafetiva indica um novo "lugar teológico", capaz de estimular o exercício teológico a partir de outro "sinal dos tempos" por meio do qual Deus se revela e se comunica.

Nesse sentido, a radicalidade da encarnação do Filho de Deus nos faz tanto voltar o olhar para a humanidade quanto nos inspira a humanizar nossas consciências e relações. Por qual motivo a experiência homoafetiva não seria de Deus? Mais ainda: Por que Deus não poderia manifestar-se por meio de uma experiência como essa?

O meu desejo profundo é o de que esse ensaio teológico não signifique apenas uma reflexão a mais, mas desperte a sensibilidade teológica e o cuidado pastoral por parte daqueles que são chamados a serem sinais da misericórdia de Deus na realidade em que se encontram.

\section{Referências}

ALISON, James. Fé além do ressentimento: fragmentos católicos em voz gay. São Paulo: É Realizações, 2010.

BESSON, Claude. Homossexuais católicos: como sair do impasse. São Paulo: Loyola, 2015.

CELAM. Documentos do CELAM: conclusões das Conferências do Rio de Janeiro, de Medellín, Puebla e Santo Domingo. São Paulo: Paulus, 2004.

CÉSAR, Chico. Dona do Dom. Disponível em: <https://www.vagalume.com.br/mariabethania/dona-do-dom.html>. Acesso em: 10 abr. 2018.

DOMINGUINHOS. Gostoso Demais. Disponível em:

<https:// www.letras.mus.br/dominguinhos/45557>. Acesso em: 10 abr. 2018.

EMPEREUR, James. L. Direção espiritual e homossexualidade. São Paulo: Loyola, 2006.

LIBANIO, João Batista. A escola da liberdade: subsídios para meditar. São Paulo: Loyola, 2010. . Eu creio, nós cremos: tratado da fé. São Paulo: Loyola, 2000.

. Teologia da revelação a partir da modernidade. São Paulo: Loyola, 2012.

MUSSKOPF, André Sidnei. Uma brecha no armário: propostas para uma teologia gay. São Leopoldo: CEBI/Fonte Editorial, 2015.

PAPA FRANCISCO. O nome de Deus é misericórdia: uma conversa com Andrea Tornielli. São Paulo: Planeta, 2016. 
RAHNER, Karl. Curso fundamental da fé: introdução ao conceito de cristianismo. São Paulo: Paulus, 1989.

RICOEUR, Paul. A Maravilha, o Descaminho, o Enigma. Revista Paz e Terra, v. 5, 1967.

RILKE, Rainer M. Poemas e cartas a um jovem poeta. Rio de Janeiro: Nova Fronteira, 2013.

SANTO AGOSTINHO. Confissões. São Paulo: Paulus, 2004.

SANTO INÁCIO, de Loyola. Exercícios Espirituais. São Paulo: Loyola, 2015.

SOBRINO, Jon. Como fazer Teologia. Proposta metodológica a partir da realidade salvadorenha e latino-americana. Perspectiva Teológica, v. 21, p. 285-303, 1989.

VIDAL, Marciano. Ética da sexualidade. São Paulo: Loyola, 2002.

VIER, Frederico (Coord.). Compêndio do Vaticano II: Constituições, Decretos, Declarações. 29.ed. Petrópolis: Vozes, 2000. 